\title{
Lasers, burns, cuts, tingles and pumps: a consideration of alternative treatments for intractable angina
}

In every cardiology clinic there are a small but increasing number of patients whose angina has survived all attempts to treat it. Such patients get little if any relief from conventional treatment. Their daily activities are severely restricted and they often require repeated hospital admissions.

What more can we do for such patients? When we consider alternative therapies we must strike a careful balance between denying a patient useful palliation because of a lack of appropriate scientific rigour and exposing a patient to poorly evaluated and potentially harmful treatments.

Many treatments have been regarded as useful in treating angina. Medical therapy with heart muscle extract, radiotherapy, anticoagulants, vitamin $\mathrm{E}$, choline, meprobamate, and cobra venom and surgical procedures such as thyroidectomy, pericardial abrasion, internal mammary ligation, and the Vineberg operation have all had their enthusiastic supporters though all have now been largely discounted.

Currently several no less ingenious methods are used to treat angina in patients in whom conventional treatment has failed. These can be loosely divided into those that aim to increase blood flow to ischaemic myocardium, and those that influence the pain pathways of the heart.

\section{Chelation therapy}

In chelation therapy, the patient is given repeated intravenous infusions of edetate disodium in an attempt to dissolve atheromatous deposits. It has been reported to relieve angina; however, its antianginal effect has not been evaluated in double blind trials. In addition chelation has important side effects such as renal tubular necrosis, hypocalcaemic tetany, bone marrow depression, hypotension, and allergic reactions. ${ }^{1}$ Chelation is still being given in some clinics, especially in the United States.

\section{Transmyocardial laser revascularisation}

Transmyocardial laser revascularisation is a novel alternative therapy for improving myocardial blood flow in patients with "inoperable" coronary artery disease. Rather than seeking to bypass or unblock epicardial artery obstructions, an $850 \mathrm{~W}$ carbon dioxide laser is used to drill up to thirty small channels into the ischaemic ventricle, thus allowing direct perfusion by ventricular blood. Bypass is not required for the short operation which is performed through a limited left thoracotomy. ${ }^{2}$ This has been reported to ease angina in the small number of patients so treated. ${ }^{3} \mathrm{~A}$ prospective randomised trial is in progress to assess the efficacy of this potentially promising new therapy.

\section{Enhanced external counterpulsation}

Another recent approach is that of enhanced external counterpulsation, in which three sets of balloons are wrapped around the muscles of the legs and thighs, and inflation is controlled by the patient's electrocardiogram such that the balloons expand during diastole and collapse during systole. The principle is that increased coronary diastolic flow will stimulate the opening of collaterals in ischaemic areas of the myocardium. Lawson et al showed that this treatment, when performed for an hour each day for 7 weeks, resulted in symptomatic improvement in 16 out of 18 severely restricted patients and thallium scintigraphy showed resolution of ischaemic defects in 12 patients. ${ }^{4}$ Controlled trials (using sham inflation) have yet to be performed.

\section{Neural methods}

Various methods have been described for the palliation of angina by interruption or modification of the afferent neural signals through which the pain is perceived. Various surgical methods have been used to interrupt the innervation of the heart, including autotransplantation, sympathectomy, and plexectomy. Autotransplantation (complete excision and reanastomosis of both atria and great vessels) is the most radical form of denervation and carries the greatest risk to life. It has been reported to be effective in a few patients ${ }^{56}$ although there seems little justification for such an aggressive approach. A recent report suggests that complete cardiac denervation could be achieved by a cryoablation technique in which liquid nitrogen is pumped through polyvinyl tubes that are inserted around the great vessels at thoracotomy. ${ }^{7}$

Sympathectomy is performed by bilateral excision of the upper three or four dorsal ganglia of the sympathetic chain (or by unilateral or occasionally bilateral paravertebral injection of alcohol). Sympathectomy was reported to be effective in reducing angina in 28 out of 52 patients ${ }^{8}$ and to increase effort tolerance on treadmill testing in most. ${ }^{9}$ There is also evidence that sympathectomy can reduce exercise induced ischaemia. ${ }^{8}$ Sympathetic fibres from the lower cervical and upper thoracic ganglia merge with vagal fibres to form the cardiac plexuses, which are located at the base of the heart and within the adventitia of the great vessels. Stripping the aorta and pulmonary arteries of their adventitia (plexectomy) therefore partially denervates the heart. Although not used in isolation this technique has been reported to improve the results of coronary bypass grafting, particularly in Prinzmetal's angina. ${ }^{10}$

The development of the gate theory of pain by Melzack and Wall in 1965 suggested that stimulation of those nerve fibres that do not transmit pain (large afferent A fibres) could reduce the input to the brain from the fibres that do (small $\mathrm{C}$ fibres) and hence reduce the 
sensation of pain. ${ }^{11}$ This theory led to spinal cord stimulation and transcutaneous electrical nerve stimulation (TENS). The precise mechanism of action for both treatments is not fully understood but both have been reported to relieve angina. Sanderson, in his review of these treatments concluded that not only were they useful for pain relief but also that they could also modify ischaemic activity. ${ }^{12}$ For spinal cord stimulation a flexible electrode is passed percutaneously (and under local anaesthetic) into the epidural space at the mid-thoracic level and positioned so as to produce a prickling sensation in the area of pain. This method has been shown to reduce ischaemic activity as well as to relieve pain. Mannheimer et al studied 10 severely restricted patients for 2 weeks. They reported a significant increase in time to angina and maximal exercise capacity on bicycle testing. ${ }^{13}$ Sanderson et al also reported that consumption of glyceryl trinitrate was considerably reduced in patients treated with spinal cord stimulation and that total ST segment depression was less at all heart rates during right atrial pacing. ${ }^{14} \mathrm{~A}$ further study reported that this treatment led to a fall in myocardial lactate metabolism. ${ }^{15}$ It is possible that direct inhibition of pain, which would prevent the reflex increase in sympathetic activity associated with angina, ${ }^{16}$ results indirectly in a reduction of ischaemic burden. The paper by de Jongste et al on page 413 provides further evidence that spinal cord stimulation does not simply abolish chest pain but also affects the ischaemia, reducing the frequency and duration of transient ischaemic episodes during ambulatory monitoring. ${ }^{19}$ Furthermore Andersen et al (pages 419-421) report that these beneficial effects of spinal cord stimulation do not mask the pain of acute myocardial infarction. ${ }^{20}$

With transcutaneous electrical nerve stimulation (TENS) an electrode is placed over the site of pain and a second electrode is sited on the other side of the spine in the same dermatome and connected to a battery-powered neurostimulator to produce a tingling sensation. This method has been shown to have reduced angina and glyceryl trinitrate consumption, ${ }^{17}$ increased work capacity, and reduced maximal ST depression..$^{18}$ Although it has been suggested that transcutaneous electrical nerve stimulation might work by enhancing production of endogenous opiates, naloxone does not abolish its beneficial effects, ${ }^{21}$ unlike its effect on acupuncture. ${ }^{22}$

It is sometimes very difficult to know where to go next with the patient with intractable angina who has run the gauntlet of all conventional treatments, but every avenue must be explored in an attempt to improve quality of life in the patient with intractable angina. Which of the alternative treatments should be used and which avoided? Most of the alternative treatements described here have not been rigorously evaluated in randomised trials because often this is either impractical or unethical, and mechanisms of action are not clear. The placebo effect has played, and doubtless will continue to play, an important part in the treatment of angina both conventional and alternative. It is important, however, to distinguish between treatments with side effects and those that are safe. Chelation therapy, which can be dangerous and which could be evaluated in a properly structured ran- domised trial, should not be used until those trials are performed. Despite their apparent effectiveness and safety TENS and spinal cord stimulation are probably underused and should be considered before the patient is subjected to less tried treatments. Though we should avoid using any treatment that is both unproven and potentially dangerous we should not become complacent about having done all we can without exploring alternative therapies, especially when these are relatively safe.

DAVID MULCAHY

CHARLES KNIGHT

ROD STABLES

Royal Brompton National Heart and Lung Hospital, KIM FOX

Sydney Street,

London SW3 $6 \mathrm{NP}$

1 Diagnostic and therapeutic technology assessment. Chelation therapy (questions and answers) $¥ A M A$ 1983;250:672.

2 TMR clinical reports (quarterly publication of PLC systems inc.) 1993; 1:1-4.

3 Mirhoseini M, Shelgikar S, Cayton M. Transmyocardial laser revascularization: a review. Fournal of Clinical Laser Medicine and Surgery 1993;11: $15-9$.

4 Lawson WE, Hui JCK, Soroff HS, Zheng ZS, Kayden DS, Sasvary D et al. Efficacy of enhanced external counterpulsation in the treatment of angina pectoris. Am $\mathcal{f}$ Cardiol 1992;70:859-62.

5 Bertrand ME, Lablanche JM, Tilmant PY, Ducloux G, Warembourg $H_{3}$ Soots G. Complete denervation of the heart (autotransplantation) for treatment of severe, refractory coronary spasm. Am $\mathcal{F}$ Cardiol 1981 47:1375-8.

6 Clark DA, Quint RA, Mitchell RL, Agnell WW. Coronary artery spasm. Medical management, surgical denervation and autotransplantation. $\mathcal{F}$ Thorac Cardiovasc Surg 1977;73:332-9.

7 Gaer JAR, Gordon L, Wharton J, Polak JM, Taylor KM, McKenna W, Parker DJ. Intractable chest pain in cardiomyopathy: treatment by a novel technique of cardiac cryodenervation with quantitative immunohistochemical assessment. Br Heart $f$ 1993;70:574-7.

8 Birkett DA, Apthrop GH, Chamberlain DA, Hayward GW, Tuckwell EG. Bilateral upper thoracic sympathectomy in angina pectoris: results in 52 cases. $B M F$ 1965;ii: $187-90$.

9 Apthorp GH, Chamberlain DA, Hayward GW. The effects of sympathectomy on the electrocardiogram and effort tolerance in angina pectoris Br Heart f 1964;26:218-25.

10 Betrieu A, Pomar J, Bourassa MG, Grondin CM. Influence of partia sympathetic denervation on the results of myocardial revascularization in variant angina. Am f Cardiol 1983;51:661-7.

11 Melzack R, Wall PD. Pain mechanisms: a new theory. Science 1965; 150:971-9.

12 Sanderson JE. Electrical neurostimulators for pain relief in angina. $\mathrm{Br}$ Heart F 1990;63:143-4.

13 Mannheimer C, Augustinsson LE, Carlsson CA, Manhem $\mathrm{K}$ Wilhelmsson C. Epidural spinal electrical stimulation in severe angina pectoris. Br Heart $f$ 1988;59:56-61

14 Sanderson JE, Brooksby P, Waterhouse D, Palmer RBG, Neubauer K. Epidural spinal electrical stimulation for severe angina: a study of its effects on symptoms, exercise tolerance and degree of ischaemia. Eur Heart $\mathcal{f}$ 1992;13:628-633.

15 Mannheimer C, Eliasson T, Andersson B, Bergh C-H, Augustinsson LE Emanuelsson $\mathrm{H}$, et al. Effects of spinal cord stimulation in angina pectoris induced by pacing and possible mechanisms of action. BMf 1993 307:477-80.

16 Robertson RM, Bernard Y, Robertson D. Arterial and coronary sinus catecholamines in the course of spontaneous coronary artery spasm. $A m$ Heart $\mathcal{f} 1983 ; 105: 901-6$.

17 Mannheimer C, Carlsson CA, Emanuelsson H, Vedin A, Waagstein F, Wilhelmsson $C$. The effects of transcutaneous nerve stimulation in patients with severe angina pectoris. Circulation 1985;71:308-16.

18 Mannheimer C, Carlsson CA, Ericson K, Vedin A, Wilhelmsson C. Transcutaneous nerve stimulation in severe angina pectoris. Eur Heart $\mathcal{F}$ 1982;3:297-302.

19 de Jongste MJL, J Haaksma, Hautvarst RWM, Hillege HL, Meyler PWJ, Staal MJ, et al. Effects of spinal cord stimulation on myocardial ischaemia during normal activity in patients with severe coronary artery disease: a prospective ambulatory electrocardiographic study. $\mathrm{Br} \mathrm{Heart} f$ 1994;71:413-8.

20 Andersen $\mathrm{C}$, Hole $\mathrm{P}$, Oxhoj $\mathrm{H}$. Does pain relief with spinal cord stimulation for angina conceal myocardial infarction? Br Heart $\mathcal{f} 1994 ; 71$ 419-21.

21 Mannheimer C, Emanuelsson H, Waagstein F, Wilhelmsson C. Influence of naloxone on the effects of high frequency transcutaneous electrical nerve stimulation in angina pectoris induced by atrial pacing. Br Heart $f$ 1989;62:36-42.

22 Thompson JW. Opiod peptides. BMF 1984;288:259-60. 